\title{
SECRETIN IN RELATION TO DIABETES MELLITUS
}

By F. A. BAINBRIDGE, M.A., M.D., Gordon Lecturer in Experimental Pathology, Guy's Hospital, AND A. P. BEDDARD, M.A., M.D., Assistant Physician, Guy's Hospital.

From the Gordon Laboratory, Guy's Hospital

(Received Fuly 3oth, 1906)

\section{SECTION I}

\section{THE TREATMENT OF DIABETES WITH SECRETIN}

The relationship between the pancreas and diabetes has long been recognised, and it has been supposed that many cases of diabetes result from the deficiency or absence of an internal secretion normally produced by the pancreas. Starling suggested that secretin might furnish the stimulus not only to the external but also to this internal secretion, and that it might prove to be of value in the treatment of diabetes. But Spriggs, who injected intravenously once a day 5 c.c. of a secretin solution freed from depressor substance, obtained a negative result in a patient who died of coma a week after the treatment had been begun.

Recently Moore, working with Edie and Abram, has published the results obtained by giving secretin by the mouth to three patients suffering from diabetes. Their first case-a man aged 25-at the beginning of the treatment was passing 40-65 grms. of sugar daily on a diabetic diet with phenacetin. He then received 30 c.c. of secretin solution three times daily. After a latent period of three weeks the sugar fell suddenly to 32 grms., and for several weeks varied from 2I-30 grms. daily. After four months' treatment with secretin the urine became free from sugar, and the patient gained in weight. The patient returned to work, and the secretin treatment was discontinued. Six months later he returned to the Hospital suffering from phthisis. His urine contained about 120 grms. of sugar daily; secretin was again administered, but without effect. The other two 
cases were children aged 7 and 9 respectively. In the first, the secretin treatment was begun simultaneously with the administration of a rigid diabetic diet; the quantity of sugar in the urine gradually fell, and the urine became sugar free at the end of forty-six days. The second child was put upon a diabetic diet together with small quantities of carbohydrate; twelve days later treatment with secretin was begun and in twenty-four days the urine was sugar free. Moore suggests that the extract of duodenal mucous membrane supplied to the pancreas a chemical excitant, which was lacking in the diabetic patients; this caused the pancreas to resume its formation of internal secretion, and as a result the patients regained the power of metabolising carbohydrate, and retained this power for some time after the omission of the secretin but not of the strict diet:

In all of these cases the treatment by secretin was combined with a diabetic diet more or less rigid. It is necessary, therefore, to consider whether results similar to those observed by Moore are seen in similar cases of diabetes treated by dieting alone. Clinically, diabetes may be divided into two grades of severity, mild and severe. In the first, the dextrose in the urine appears to come only from the carbohydrate of the food. When such a patient is placed on a rigid diabetic diet, his urine may be expected to become sugar free within a week, and not to give a reaction with ferric chloride; the patient rapidly improves and may regain a very considerable power of utilising carbohydrate food. The other type of the disease is different clinically, in that dextrose is still passed out, although the patient is having the most rigid diet which can be devised. In the most severe cases the patient, when on an ordinary diet, passes out much sugar and diacetic acid; when placed on a rigid diet the sugar in the urine decreases for a time, but the diacetic acid and acid intoxication rapidly increase, so that within a fortnight the patient may suffer from nausea, loss of appetite and other symptoms of threatened coma, from which he may or may not spontaneously recover. However long the strict diet is maintained, the sugar in the urine never disappears, and very often it tends to rise after the initial fall. None of Moore's cases were of such severity as this. The mildest cases of this type give a very 
different response to treatment by diet. Such patients, when on an ordinary diet, may or may not pass out diacetic acid besides sugar; when placed on a rigid diet, diacetic acid is passed and the sugar after fluctuations decreases, so that the urine may become sugar free in a month or two. Considerable power of utilising carbohydrate may be gained, the diacetic acid reaction may disappear, and the patient may pass for a time into the mild type of diabetes. From the histories of Moore's cases, and from the analyses of the urines given by Edie and Whitley, it would appear that Cases II and III were of this nature, and that of the two, Case II was rather the more severe. It is a well known fact that cases rather more severe than either of these may become sugar free after a long period of dieting, but that if they go back to ordinary diet for several months and then come under treatment again, it may be found that the type of disease has undergone a considerable change for the worse; this appears to have happened in Moore's first case. In fact there is no evidence to show that any of Moore's cases were of such severity that dieting alone would not have accounted for the observed disappearance of sugar from the urine. It seemed desirable, therefore, to test the effect of secretin on diabetics of a rather more severe type.

Methods.-The extracts used were obtained from the intestinal mucous membrane of pigs, sheep, and other animals. The upper two or three feet of the intestine were used, and the extracts were made by the method described by Bayliss and Starling. In a majority of cases the activity of the extracts was tested by experiment on animals and, if need arose, the extracts were concentrated. In the first instance the extract was injected subcutaneously in IO-20 c.c. doses, but the patients objected to the injections as they caused much pain locally and sometimes severe headache; consequently, after one or two injections the secretin was given only by mouth. Each patient received 30 c.c. two or three times daily, one hour after food. The total urine for the 24 hours was collected and measured each day; the sugar was estimated by Pavy's method, and the ferric chloride test for diacetic acid was made use of. 


\section{Description of CAsEs}

We have treated three cases of the severe type of diabetes with secretin. Case I was clinically the least severe; Case III was suffering from diabetes in its most severe form, and Case II was rather less severe than this.

Case I.-A boy, aged I5, was admitted into Guy's Hospital on January 31st, 1906, for thirst and wasting. These symptoms had been noticed only since the previous December.

On admission the patient was found to be extremely thin; his urine contained a large amount of sugar, but neither acetone nor diacetic acid. For two days he was placed on an ordinary diet, and on February 2nd, this was changed to a rigid diabetic diet with the daily addition of 35 grams of carbohydrate given at dinner time in the form of potatoes. On February 26th, the daily allowance of carbohydrate was reduced to 25 grams. On February 28th, the urine began to give a reaction with ferric chloride, which disappeared on March

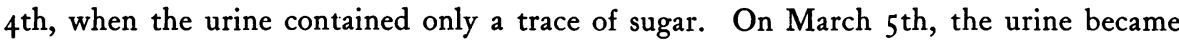
sugar free after thirty-two days of treatment by dieting. Between February 2nd and March Ist, the patient received 20 grams of sodium bicarbonate daily; this was stopped as the urine became alkaline to litmus on March Ist.

On March 6th, the patient was put back upon the ordinary full hospital diet, and on March 8th, Io c.c. of secretin solution were injected subcutaneously. Between March 9 th and 19th the patient received 30 c.c. of secretin solution by the mouth, either once, twice or three times a day. During this period the urine contained increasing quantities of sugar, but gave no diacetic reaction.

On March 20th, the patient was put on the most rigid diabetic diet which could be devised, it contained no milk, and the substitutes for bread used were Protene bread and biscuits, and Callard's brown caseoid bread. The diacetic reaction in the urine returned at once, and the sugar diminished, but had not disappeared at the end of nine days.

The characters of the urine, the amounts of sugar passed, and other details are given in the following table :-

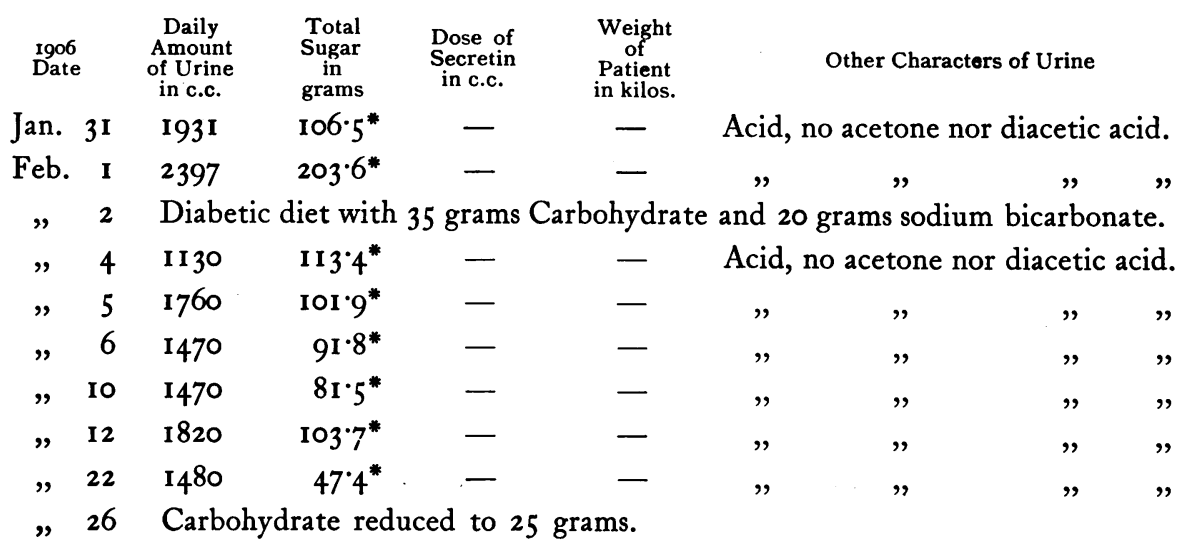




\begin{tabular}{|c|c|c|c|c|c|c|c|c|c|}
\hline $\begin{array}{l}\text { 1906 } \\
\text { Date }\end{array}$ & & $\begin{array}{l}\text { Daily } \\
\text { Amount } \\
\text { of Urine } \\
\text { in c.c. }\end{array}$ & $\begin{array}{l}\text { Total } \\
\text { Sugar } \\
\text { in } \\
\text { grams }\end{array}$ & $\begin{array}{l}\text { Dose of } \\
\text { Secretin } \\
\text { in c.c. }\end{array}$ & $\begin{array}{l}\text { Weight } \\
\text { of } \\
\text { Patient } \\
\text { in kilos. }\end{array}$ & \multicolumn{4}{|c|}{ Other Characters of Urine } \\
\hline Feb. & & 2470 & $99^{\circ} 8$ & - & - & \multicolumn{4}{|c|}{ Acid, faint diacetic reactio } \\
\hline Mar. & $\mathbf{I}$ & 2850 & $105 \cdot 8$ & - & - & \multicolumn{4}{|c|}{ Alkaline $\quad \# \quad}$, \\
\hline " & 2 & I550 & $53^{\cdot I}$ & - & - & \multicolumn{4}{|c|}{ Neutral, weak , } \\
\hline " & 3 & 890 & $14^{\circ} 8$ & - & 345 & Acid, & & & " \\
\hline$"$ & 4 & 1220 & Trace & - & - & \multicolumn{4}{|c|}{ no diacetic reaction } \\
\hline " & 5 & 1220 & Absent & - & $34^{\circ} 9$ & ", & ", & , & ", \\
\hline & & \multicolumn{8}{|c|}{ March 6th, the patient was given ordinary diet. } \\
\hline " & 6 & 2400 & $89 \cdot 1$ & 一 & - & \multicolumn{4}{|c|}{ Acid, no diacetic reaction. } \\
\hline$"$ & 7 & 2360 & $147^{\circ} 5$ & - & $33 \cdot 8$ & $"$ & " & , & $"$ \\
\hline , & 8 & 2410 & $180 \cdot 7$ & \multicolumn{2}{|c|}{ Io (subcut.) - } & $"$ & $"$ & , & $"$ \\
\hline ", & 9 & 2620 & $218 \cdot 9$ & \multicolumn{2}{|c|}{30 (mouth) 33.8} & " & " & , & $"$ \\
\hline$"$ & 10 & 2540 & $205 \cdot 7$ & 30 & - & $"$ & $"$ & , & " \\
\hline " & II & 3180 & $242 \cdot 2$ & 60 & $34^{\cdot I}$ & $"$ & " & , & $"$ \\
\hline " & 12 & 2660 & $216 \cdot 5$ & 60 & - & $"$ & $"$ & , & $"$ \\
\hline$"$ & 13 & 2950 & $247^{\circ} 4$ & 90 & $34^{\circ} 6$ & " & , & ", & , \\
\hline " & 14 & 3530 & $273 \cdot 3$ & 90 & 一. & $"$ & $"$ & , & $"$ \\
\hline$"$ & 15 & 2970 & $266 \cdot 5$ & 90 & $34^{\circ} 9$ & $"$ & $"$ & , & $"$ \\
\hline " & 16 & 3130 & $288 \cdot 2$ & 60 & - & $"$ & $"$ & , & ", \\
\hline " & 17 & 2470 & 233.5 & 60 & $35^{\circ} 0$ & ", & " & , & $"$ \\
\hline$"$ & 18 & 3280 & $330 \cdot 6$ & 60 & - & $"$ & & , & $"$ \\
\hline , & I9 & 2500 & $233^{\circ} 2$ & 90 & $35^{\bullet} 2$ & " & $"$ & , & $"$ \\
\hline
\end{tabular}

March 2oth, patient was put on a rigid diabetic diet.

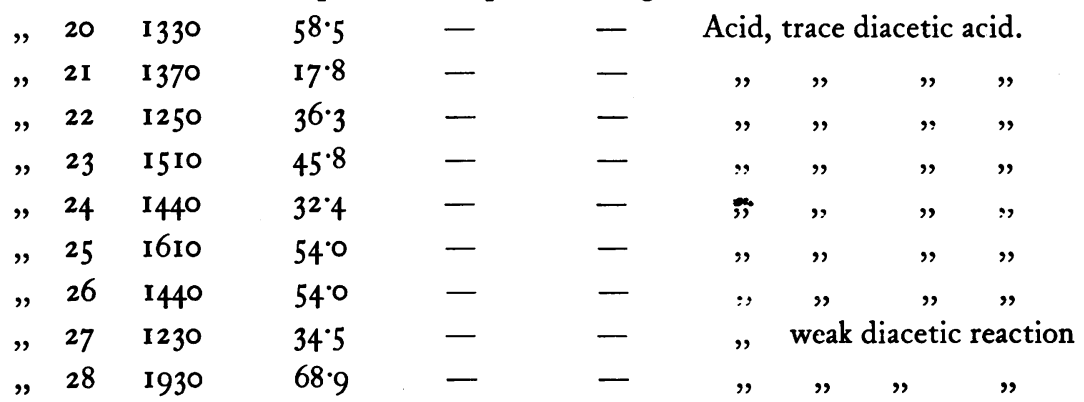

Estimations marked * were made by the Ward Clerk before the case came into our hands.

After leaving the hospital the boy went back to an ordinary diet for several months. Recently he has been under the observation of one of us; his urine contains much sugar and diacetic acid, and can no longer be made sugar free by a restricted diet.

Case II.-A man aged 49, was admitted into Guy's Hospital on March 3rd, 1906, for cough and shortness of breath. He had been in the hospital previously and was known to have suffered from phthisis and diabetes since December, 1903.

On admission the patient was found to be thin, he was suffering from chronic fibroid phthisis, and throughout his stay in the hospital showed no pyrexia ; his urine contained 
a moderate amount of sugar, gave no diacetic acid reaction and did not contain albumen. He was placed at once upon a rigid diabetic diet, together with 35 grams carbohydrate given daily at dinner time in the form of potatoes. The same diet was continued during and subsequent to the period of treatment with secretin.

On March 6th, the urine began to give a reaction with ferric chloride which increased in intensity until, on March 12 th and 13 th, it was a strong reaction; from this date the intensity decreased, and on March 2Ist, the reaction was only weak. On March 7 th, the patient felt sick and lost his appetite; these symptoms of incipient coma lasted for two days and did not recur.

On March 6th, ro c.c. of secretin solution were injected subcutaneously and on March 8th and 9th, 20 c.c. These injections gave the patient not only a severe headache, lasting several hours, but the last produced such a severe fall in the blood pressure as to be dangerous.

The output of sugar in the urine showed no tendency to diminish in amount during or after the period of treatment with secretin; on the whole it rose slowly and steadily throughout the period of observation.

The progress of the case is shown in the following table :-

\begin{tabular}{|c|c|c|c|c|c|c|c|c|}
\hline $\begin{array}{l}\text { rgo6 } \\
\text { Date }\end{array}$ & & $\begin{array}{c}\text { Daily } \\
\text { Amount } \\
\text { of Urine } \\
\text { in c.c. }\end{array}$ & $\begin{array}{l}\text { Total } \\
\text { Sugar } \\
\text { in } \\
\text { grams }\end{array}$ & $\begin{array}{l}\text { Dose of } \\
\text { Secretin } \\
\text { in c.c. }\end{array}$ & $\begin{array}{l}\text { Weight } \\
\text { of } \\
\text { Patient } \\
\text { in kilos. }\end{array}$ & \multicolumn{3}{|c|}{ Other Characters of Urine } \\
\hline Mar. & 3 & 950 & $31 \cdot 2$ & - & - & \multicolumn{3}{|c|}{ No diacetic reaction. } \\
\hline ", & 4 & 1420 & $45 \cdot 3$ & - & - & 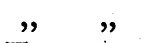 & & \\
\hline " & 5 & 1570 & $52 \cdot 3$ & 一 $\cdots$ & - & Trace „, & & \\
\hline " & 6 & $\mathbf{1} 700$ & $54 \%$ & Io (subcut.) & - & \multicolumn{3}{|c|}{ Moderate diacetic reaction. } \\
\hline ” & 7 & 1830 & $63 \cdot 2$ & - & - & " & ; & " \\
\hline " & 8 & 1900 & $65^{\cdot 1}$ & 20 (subcut.) & 547 & " & " & " \\
\hline , & 9 & 2160 & $79^{\circ} 0$ & 20 (subcut.) & ) - & , & " & ", \\
\hline , & IO & r670 & $62 \cdot 2$ & 30 (Mouth) & $54^{\cdot 2}$ & " & " & $"$ \\
\hline , & I I & 1430 & $63 \cdot 8$ & 60 & - & $"$ & " & ” \\
\hline " & 12 & 1970 & $75^{\circ} 2$ & 60 & $55^{\circ} 2$ & Strong & " & $"$ \\
\hline ” & I3 & I770 & $70 \cdot 8$ & 90 & - & $"$ & " & $"$ \\
\hline , & 14 & 1810 & $88 \cdot 7$ & 90 & $54^{\circ 2}$ & Moderate & " & $"$ \\
\hline " & I 5 & 1850 & $89 \cdot 8$ & 90 & - & " & $"$ & " \\
\hline " & 16 & 1730 & 857 & 60 & $54 \cdot 3$ & " & " & ” \\
\hline " & 17 & 1630 & $8 I \cdot 8$ & 60 & - & $\quad$, & ", & $"$ \\
\hline " & 18 & 1490 & $86 \cdot 2$ & 60 & 543 & Weak & " & " \\
\hline " & 19 & 1630 & $85 \cdot 3$ & 90 & $55^{\circ} \circ$ & " & " & " \\
\hline " & 20 & 1420 & $76 \cdot 8$ & 90 & - & " & " & $"$ \\
\hline " & $2 I$ & 1920 & $86 \cdot 5$ & 90 & $54^{\circ} 9$ & " & " & " \\
\hline " & 22 & 2110 & $97^{\circ} 7$ & 90 & - & ", & ", & " \\
\hline " & 23 & 1650 & $85^{\circ} 9$ & 90 & $54^{\circ} 8$ & $"$ & " & ," \\
\hline " & 24 & 1560 & 837 & 90 & - & ", & " & ", \\
\hline " & 25 & 1270 & $70 \cdot 2$ & - & $54^{\circ} 9$ & " & " & " \\
\hline " & 26 & $134^{\circ}$ & $78 \cdot 3$ & - & - & ", & " & , \\
\hline , & 27 & 1260 & $71 \cdot 3$ & - & $55^{\circ} 9$ & " & " & $\because$ \\
\hline
\end{tabular}


Case III.-A man, aged 45, was admitted into Guy's Hospital on March Ist, I906, for thirst, polyuria and wasting. The patient had been losing weight for about a year and had noticed polyuria for six months. His daughter, aged 8, had died in the Hospital of diabetic coma just previously to his own admission. Her case is referred to as Case $I$ in Section II of this paper.

On admission the patient was found to be very wasted; his breath smelt strongly of acetone; his urine contained diacetic acid, acetone and a moderate quantity of sugar. He was placed at once on a rigid diabetic diet, together with 35 grams carbohydrate given as potatoes. The same diet was maintained until the end of the period of observation.

On March 2nd, the urine gave a moderate reaction with ferric chloride; this increased to a strong reaction on March 6th, and continued so until the end. On March 7 th, the patient complained of nausea, could eat very little and felt too ill to get up. The next day he vomited, ate practically no food, and was stupid and rather drowsy. On March 9th, the patient ate 4 ounces of ordinary bread and some milk; by the next day the symptoms of incipient coma had begun to disappear and the patient went back to his proper diet. On March 8th, the patient was given 5 grams of sodium bicarbonate; the dose was increased to 30 grams on the next day; and this quantity was given daily until March 19 th, when the urine became alkaline to litmus; after this the drug was discontinued.

On March 6th, Io c.c. of secretin solution were injected subcutaneously, and on 8th, 20 c.c. After that date 30 c.c. were given once, twice, or three times daily by the mouth until 24th. During the first ten days of the treatment by secretin the amount of sugar in the urine varied but little, although on the whole it tended to increase; but on March I9th, the output became suddenly greater and continued at this higher level during the rest of the secretin treatment and after it was stopped. The striking alterations in weight were undoubtedly due to retention of water, following the administration of sodium bicarbonate; after March 16th, the daily quantity of urine rose and the stored up fluid was got rid of.

The following table shows the progress of the case :-

\begin{tabular}{|c|c|c|c|c|c|c|c|c|c|}
\hline \multirow{2}{*}{$\begin{array}{l}\text { Igo6 } \\
\text { Date } \\
\text { Mar. }\end{array}$} & & $\begin{array}{l}\text { Daily } \\
\text { Amount } \\
\text { of Urine } \\
\text { in c.c. }\end{array}$ & $\begin{array}{c}\text { Total } \\
\text { Sugar } \\
\text { in } \\
\text { grams }\end{array}$ & $\begin{array}{l}\text { Dose of } \\
\text { Secretin } \\
\text { in c.c. }\end{array}$ & $\begin{array}{l}\text { Neight } \\
\text { of } \\
\text { Patient } \\
\text { n kilos. }\end{array}$ & \multicolumn{4}{|c|}{ Other Characters of Urine } \\
\hline & 2 & 2160 & $79^{\circ} 0$ & - & - & Acid & modera & ace & ction \\
\hline$"$ & 3 & 2010 & $75^{\circ} 4$ & - & $46 \cdot 7$ & , & $"$ & $"$ & $"$ \\
\hline " & 4 & 2150 & $8 I^{\circ} 0$ & - & 一. & , & ", & " & ", \\
\hline " & 5 & 2430 & 834 & 一 & $47^{\cdot 2}$ & , & , & " & " \\
\hline , & 6 & 2820 & $67 \cdot 8$ & IO (subcut.) & - & , & strong & , & , \\
\hline$"$ & 7 & 3290 & $86 \cdot 1$ & - & $47^{\bullet} 2$ & ", & , & $;$ & " \\
\hline " & 8 & 2470 & $71^{\circ} 0$ & 20 (subcut.) & - & , & ", & ", & " \\
\hline , & 9 & 2240 & $9 I^{\circ} \circ$ & 30 (mouth) & $46 \cdot 5$ & ", & , & " & " \\
\hline " & 10 & 2150 & $96 \cdot 9$ & 30 & 一 & " & , & ", & " \\
\hline , & I I & 2250 & $94 \div 5$ & 60 & $48 \cdot 5$ & ", & $"$ & $"$ & " \\
\hline " & I 2 & 2580 & $97^{\circ} \circ$ & 60 & - & " & 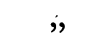 & ", & " \\
\hline
\end{tabular}




\begin{tabular}{|c|c|c|c|}
\hline $\begin{array}{l}1906 \\
\text { Date }\end{array}$ & $\begin{array}{c}\text { Daily } \\
\text { Ambunt } \\
\text { of Urine } \\
\text { in c.c. }\end{array}$ & $\begin{array}{l}\text { Total } \\
\text { Sugar } \\
\text { in } \\
\text { grams }\end{array}$ & $\begin{array}{l}\text { Loss of } \\
\text { Secretin } \\
\text { in c.c. }\end{array}$ \\
\hline Mar. I3 & 2470 & $95 \cdot 4$ & 90 \\
\hline , I4 & 2350 & $89^{\circ} 4$ & 90 \\
\hline 15 & 2620 & $102 \cdot 3$ & 90 \\
\hline,$\quad 16$ & 3330 & $120 \cdot 6$ & 60 \\
\hline,$\quad 17$ & 3590 & I I I $\cdot 7$ & 60 \\
\hline,$\quad 18$ & 3600 & 108.4 & 60 \\
\hline 19 & 4300 & $152 \cdot 3$ & 90 \\
\hline " 20 & 3680 & I 34.3 & 90 \\
\hline$\Longrightarrow \quad 2 \mathbf{I}$ & 4210 & $169 \cdot 8$ & 90 \\
\hline$\Rightarrow \quad 22$ & 4580 & 183.2 & 90 \\
\hline \# 23 & 4600 & 184.7 & 90 \\
\hline " 24 & 4 I 30 & 163.3 & 90 \\
\hline " 25 & 3950 & $145^{\circ} 2$ & - \\
\hline , 26 & 4380 & 158.8 & - \\
\hline , 27 & 4050 & I $54^{\circ} 6$ & - \\
\hline
\end{tabular}

\begin{tabular}{|c|c|c|c|c|}
\hline $\begin{array}{l}\text { Weight } \\
\text { of } \\
\text { Patient } \\
\text { in kilios }\end{array}$ & & her Chara & ters of Urin & \\
\hline $51 \cdot 0$ & Acid, & strong & diacetic & reaction \\
\hline - & , & ", & $"$ & , \\
\hline $51 \cdot 4$ & , & ", & " & , \\
\hline - & $"$ & " & $"$ & $"$ \\
\hline $49^{\circ} 8$ & , & , & ", & , \\
\hline - & Neutral & 1 & ", & " \\
\hline $47 \cdot 7$ & Alkaline & e , & $"$ & ; \\
\hline- & Acid & , & ", & " \\
\hline $46 \cdot 8$ &,$\bullet$ & , & , & " \\
\hline- & $"$ & " & ", & " \\
\hline $47^{\cdot I}$ & " & $"$ & $"$ & $"$ \\
\hline- & , & , & , & , \\
\hline $46 \cdot 8$ & , & , & , & , \\
\hline- & $"$ & $"$ & ", & $"$ \\
\hline- & $"$ & , & " & $"$ \\
\hline
\end{tabular}

\section{Conclusions}

It will be seen from the preceding account that in three cases of the severe type of diabetes, the administration of secretin by the mouth had no influence whatever upon the output of sugar in the urine. And yet it was possible in Case I, after a latent period of more than a month, to abolish the glycosuria by means of dieting. It seems probable that Moore's cases were of a kind similar to this one, and that the long latent period, which he attributed to secretin, belonged to the diet. There appears to us to be no sufficient evidence that secretin, when given by the mouth, can abolish or influence the glycosuria of severe diabetes.

In the light of Starling's experience, that in animals secretin is not absorbed when introduced even in large amount into the alimentary canal, it seemed desirable to try the effect of full doses of secretin given subcutaneously. The number of subcutaneous injections given by us is too small to enable us to form any opinion of their value in the treatment of diabetes. 


\section{SECTION II.-PROSECRETIN IN DIABETES}

The treatment of diabetes mellitus with secretin is based primarily upon the assumption that prosecretin is deficient in, or absent from, the intestinal mucous membrane of either all, or at least some, diabetic patients. It seemed desirable to ascertain whether this assumption was justified by the facts. We have, therefore, examined for prosecretin the intestines of six diabetic patients. As a control, we have compared the results so obtained with those given by the intestines taken from nine patients dying of other diseases.

\section{Methons}

The duodenum and upper part of the small intestine was obtained from diabetic and other patients as soon as possible after death; the mucous membrane was scraped off, and an acid extract made according to the method described by Bayliss and Starling. The activity of the extract was tested by intravenous injection into cats or dogs, anaesthetised with ether or A. C. E. mixture, and having a cannula in the pancreatic duct. In every experiment, the effect of the extract from diabetic mucous membrane was compared with that obtained by injecting secretin made either from normal animals or from nondiabetic patients. Many of the diabetic extracts were tested twice in different animals. As a rule, the blood pressure was recorded in the experimental animals, and the depressor effect observed. Further details appear in the protocols.

\section{Results}

A. Non-Diabetic Patients.-It was necessary, in the first place, to determine whether prosecretin disappeared shortly after death or whether its presence could always be demonstrated in the duodenal mucous membrane, even one or two days post mortem. The duodenum was taken from the bodies of nine patients at varying intervals after death ; it yielded secretin in every case. The results of these control experiments are indicated in the following table :- 


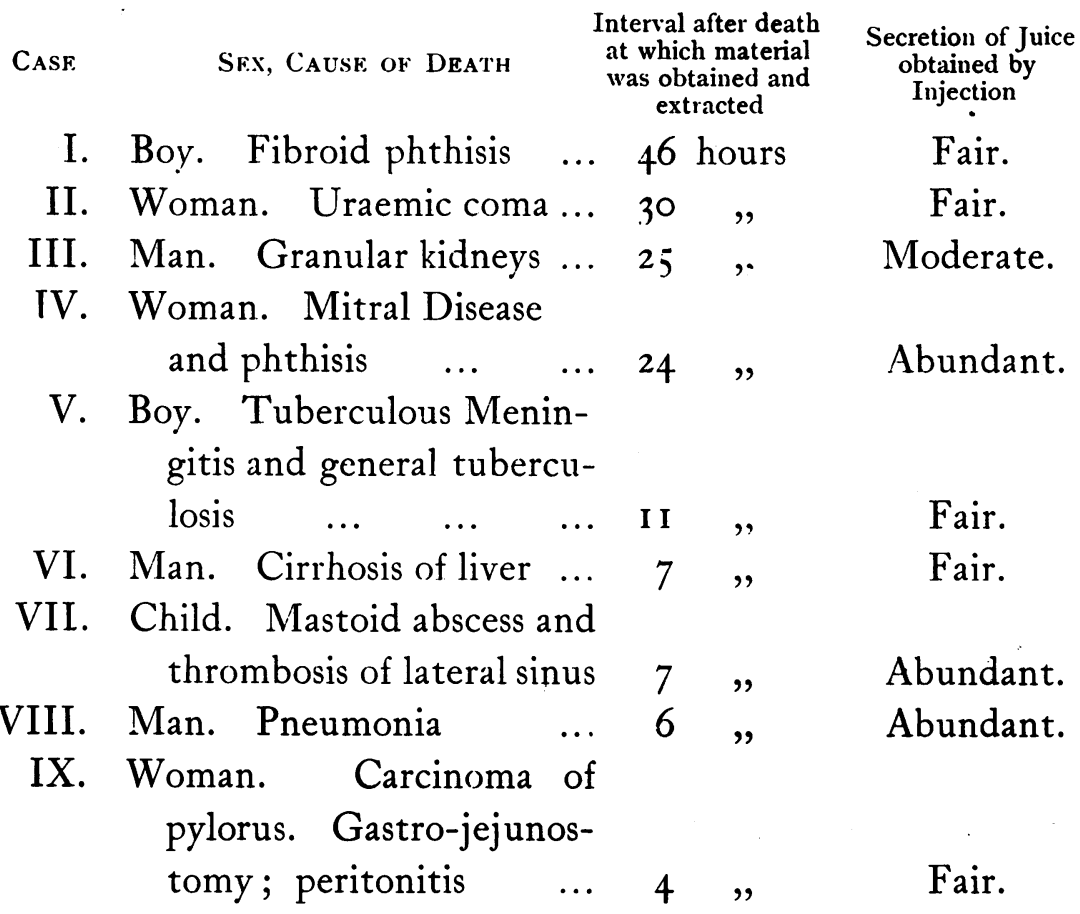

From this table it is obvious that, although it is possible that there is some post-mortem disappearance of prosecretin, the duodenal mucous membrane contains a fairly large quantity of it as long as two days after death.

The following protocol, which will serve as an example, shows the presence of a normal quantity of prosecretin 24 hours after death :-

Experiment IV.-Woman, aged 20, died from mitral disease and phthisis. Duodenum obtained 24 hours after death; extract made at once in the usual way.

Injected 2 c.c. extract Blood pressure fell from $130-85$ into cat anaesthetised $\mathrm{mm} . \mathrm{Hg}$. Secretion of juice with ether. 0.5 c.c. Subsequent injections yielded a similar secretion of juice.

B. Diabetic Patients. - We have had the opportunity of examining the duodenum of six diabetic patients for the presence of 


\section{INJECIION}

4 c.c. extract from diabetic case I ... ...

2 c.c. , , non-diabetic case IV. ...

5 c.c. ,

5 c.c. ,

2 c.c. , ,

4 c.c. ,

5 c.c. , ,
,

diabetic case I $\ldots . \quad \ldots$

$,,, \ldots, \ldots$

non-diabetic case IV $\ldots$

diabetic case $\mathrm{I} \quad \ldots \quad \ldots$

normal cat $\ldots \quad \ldots$
Blood Pressure Flow of Juice

I30 fell to $80 \quad \mathrm{Nil}$.

I $30,,, 85 \quad 0.5$ c.c.

I I0 , , $70 \quad$ Nil.

I 10, ,60 Nil.

IIO,, $70 \quad 0.5$ c.c.

I Iо , ,70 Nil.

I $10, \quad, 65 \quad 0.5$ c.c.

Case II.-A man, aged 27, was originally admitted into Guy's Hospital on September 16th, 1904, for weakness, thirst and polyuria of two months' duration. On admission he was found to be thin; his urine measured about six litres and contained $5 \%$ sugar, acetone and diacetic acid. He was dieted and his urine became sugar-free on November zoth, and at the same time the diacetic reaction disappeared. The man left the hospital on February 16th, 1905.

He was readmitted on May 18th, 1906, for congenital lamellar cataract. He was passing daily about $20-30$ litres of urine containing about $\mathrm{I} \cdot 5 \%$ dextrose. On June 9 th, he developed 'air-hunger' and died, comatose, on the next day. The post-mortem examination showed that the body was much wasted, and that all the viscera were normal excepting for some old pleural adhesions ; the pançreas weighed 54 grams, and was microscopically normal.

The intestines were received 14 hours after death and an acid extract was made at once. The extract was tested upon a cat anaesthetised with ether, and compared with extracts made from the intestines of a normal dog and of a cat fourteen days after removal of the pancreas. The following protocol gives the results of the experiment :-

\section{Injection Blood Pressure Flow of Juice}

2 c.c. extract from depancreatised cat $\ldots \quad 150$ fell to $70 \quad 0.5$ c.c.

3 c.c. $, \quad, \quad$ patient $\ldots \quad \ldots \quad \ldots \quad 140 \%, 60 \quad$ I drop

2.5 c.c. ", , depancreatised cat $\ldots$ I I0, 775 0.3 c.c.

2.5 c.c. " $\quad$, normal $\operatorname{dog} \quad \ldots \quad \ldots \quad 145 \quad, \quad, 60 \quad 0.7$ c.c.

5 c.c. $"$, depancreatised cat $\ldots$ I $20, \# 50$ I 0 c.c.

The extract from this patient was tested thoroughly on two other animals and gave generally no flow of juice at all, or in a few instances one drop, even when injected in doses of 10 c.c.

Case III.-Man, aged 30 years, was admitted into St. Bartholomew's Hospital for wasting and polyuria. He had been well until ten months previously, since when he had lost two stone in weight and had passed large quantities of urine. While in the hospital he passed daily 3-5 litres of urine containing 100-200 grams of sugar; the urine contained diacetic acid. Eight days after admission the patient became comatose, and died 24 hours later. Post-mortem.-All the viscera appeared to be healthy, and showed very little post- 
mortem change. The pancreas weighed 65 grams; it was small and soft, and microscopically normal, excepting perhaps that the section showed a slight excess of fibrous tissue round the small ducts in the gland.

The duodenum was obtained 25 hours after death, and an acid extract of the mucous membrane was made at once. A cat was anaesthetised with ether, and cannulae were placed in the pancreatic duct and one jugular vein. The effects of injecting the extract from the patient's duodenum were compared with those yielded by normal dog's secretin, and are recorded in the following protocol :-

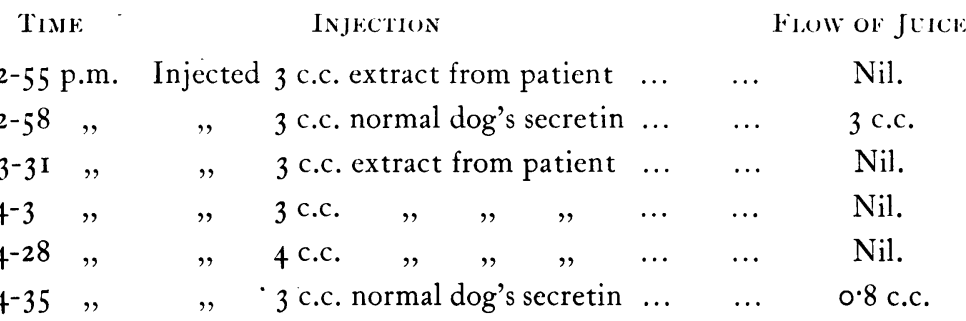

The extract from the paticnt was concentrated and contained much depressor substance.

Case IV.-Man, aged 48, was admitted into St. George's Hospital, under Dr. Ogle, on April 23rd, 1906, for phthisis and diabetes. His illness had begun gradually 18 months previously with cough, loss of appetite, progressive wasting and thirst; he did not noticc polyuria. On admission he was found to be extremely ill; the sputum contained tubercle bacilli; his legs were oedematous up to the thighs. His urine contained albumen, $8 \%$ dextrose, but not acetone. He was placed on a milk diet. The patient gradually became weaker and repeatedly vomited black blood. On April 28 th, he died from cardiac failure, not from diabetic coma.

The post-mortem examination was made 12 hours after death. Both lungs showed extensive active tuberculosis. The heart was enlarged on its right side. 'The liver weighed 53 ozs.; it was fatty and nutmeg. The pancreas weighed II 3 grains; it was normal microscopically. The stomach and intestines contained altered blood; no source of haemorrhage could be found.

The intestines were obtained 16 hours after death and were kept in ice for another 24 hours. An acid extract was then made in the usual way and tested on a cat anaesthetised with ether. The results were compared with that yielded by normal dog's secretin, as is shown in the following protocol :-

NATURE OF INJECTION

7 c.c. extract from patient

6 c.c. normal dog's secretin

8 c.c. extract from patient

IO c.c.
Blool, Pressure

... Fell from 155 to $75 \mathrm{~mm}$. Hg. Nil.

.. $\quad, \quad$ I $50,80, \quad, \quad$ I c.c.

$\ldots \quad, \quad, \quad \mathbf{1} 35,70, \quad, \quad, \quad 2$ drops

.. $, \quad, \quad$ 1 $30,70, \quad, \quad, \quad 2$ drops 
Case V.-Woman, aged 58, was admitted into St. Thomas's Hospital on May $4^{\text {th, }}$ 1906, under the care of Dr. Acland, for diabetes. She had suffered from polyuria and thirst for 5 months, and had noticed loss of weight for 3 months. On admission, the patient was found to be well nourished. Her urine contained a trace of albumen, $3 \%$ sugar, and had sp. gr. 1036. She was placed upon a diet in which the carbohydrates were slightly restricted. On May 9 th the patient became rather drowsy; the urine contained traces of diacetic acid and acetone. On the next day she was more drowsy, and the urine contained more diacetic acid and acetone. On May I I th she died in a comatose condition. Her temperature was sub-normal throughout. At the post-mortem examination all the viscera were found to be healthy, excepting the kidneys, which contained a few small abscesses due to pyelonephritis. The pancreas was normal microscopically.

There is a doubt whether the coma in this case was diabetic or uraemic. The opinion of those who observed the case clinically was that the coma was not diabetic.

The intestines were obtained 48 hours after death, having been kept in ice most of the time. The duodenal extract was made in the usual way, and tested upon a dog, anaesthetised with A. C. E. mixture. As a control secretin from a normal dog and from a fatal case of pneumonia (Case VIII of the non-diabetic patients) was injected. In the same dog the duodenal extract of diabetic Case VI was tested, and in the following protocol the results of both cases are given :-

\section{INJECTION}

Blood Pressure Flow of Juice

\begin{tabular}{|c|c|c|c|c|c|c|c|c|c|c|c|}
\hline c.c. & & & non-dial & petic Case & VII & & & & & m. & 2.0 c.c. \\
\hline 8 c.c. & " & , & diabetic & Case V & $\ldots$ & $\ldots$ & IIO & ", & 45 & " & 0.6 c.c. \\
\hline 8 c.c. & ", & ", & normal & $\operatorname{dog} \ldots$ & $\ldots$ & $\ldots$ & I 20 & ", & 40 & , & $I_{4} 4$ c.c. \\
\hline 9 c.c. & " & $"$ & diabetic & Case VI & $\ldots$ & $\ldots$ & 90 & " & 40 & " & I drop. \\
\hline 8 c.c. & ", & , & " & , & $\ldots$ & $\ldots$ & 90 & , & 40 & $"$ & I drop. \\
\hline c.c. & $"$ & " & " & ", & $\cdots$ & $\ldots$ & I 10 & , & 40 & , & I drop. \\
\hline c.c. & $"$ & ", & " & " & $\ldots$ & $\ldots$ & 90 & " & 40 & ; & I drop. \\
\hline
\end{tabular}

Case VI.-A man, aged 67, was admitted into Guy's Hospital on May I I th, 1906, in an unconscious condition. Four years previously he had begun to suffer from great thirst and an abnormally large appetite; one year later he developed cataract in each eye. He had not been feeling well for a week before admission, and on the day of admission he fell down unconscious. When admitted into the Hospital he was found to be well nourished; his urine contained $\mathbf{I} 5 \%$ sugar, diacetic acid and acetone, and amounted to 6 litres in the day; his condition was considered not to be due to diabetic coma. On May I2th he became conscious, but still remained very ill. On May I $4^{\text {th }}$ he showed marked orthopnoea, and his dyspnoea was clearly due to cardiac and general circulatory failure. On May 16th his temperature rose to $106^{\circ} \mathrm{F}$, and on the next day his left knee joint became inflamed; he passed about $150-200$ grams of sugar daily. On March I8th both knee joints were acutely inflamed, and a pericardial rub was noticed; the patient became semi-conscious and died on the next day. 
The post-mortem examination showed that the man had died of septicaemia and acute septic pericarditis. The heart muscle was fatty, the arteries atheromatous, the liver fatty, and the kidneys tough. The pancreas weighed 80 grams; microscopically it was normal.

The duodenum was received 46 hours after death, and an extract of it was made at once. The effect produced by the injection of the extract into a dog is shown in the protocol at the end of Case $V$.

\section{Conclusions}

Our observations show that only in one out of six cases of severe diabetes was prosecretin present in an amount approximating to the normal. This one case, however, is sufficient to show that an absence of prosecretin is not a necessary result of the abnormal metabolism of severe diabetes. The same thing is shown by the fact that we found prosecretin present in normal quantity in the duodenum of a cat a fortnight after the removal of the pancreas (vide protocol at the end of Case II). The cat presented all the symptoms of diabetes in a severe degree ; it had lost more than one-third of its original body-weight, the urine gave a reaction with ferric chloride, and the $\frac{D}{N}$ was about 3 .

In the other five cases of severe diabetes, prosecretin was either absent, or present in very small quantities; in the three cases of diabetic coma it was absent, and in two cases of severe diabetes, which died of intercurrent disease, it was present, but extremely scanty. There are two obvious hypotheses which could be advanced to account for the diminution or absence of prosecretin in these cases. In the first place, the acid intoxication, which almost invariably precedes the natural termination in coma, may prevent the normal production of prosecretin; on this view its absence would be a terminal result of the diabetes and would be of very little importance clinically. Secondly, it is possible that prosecretin may be very deficient or absent from the outset in the more acute and severe cases of diabetes, which rapidly progress towards a fatal issue in coma; if this were true, the absence of prosecretin might be the actual cause of such cases of diabetes. But it would be necessary to assume also that secretin is the stimulus to the internal secretion of the pancreas, and that the pancreas is functionally, as well as microscopically, normal. 
We have attempted to decide between these two hypotheses by producing an artificial acid-intoxication in animals, and then examining their intestines for the presence of secretin. For this purpose rabbits were used, and dilute phosphoric acid was administered by the alimentary canal; the alkalinity of the blood-serum was estimated by Wright's method and is expressed as the strength of sulphuric acid necessary to neutralise it.

Experiment.-Rabbit.

\begin{tabular}{|c|c|c|c|c|}
\hline $\begin{array}{l}\mathrm{Da} \\
\mathrm{I} 9\end{array}$ & & $\begin{array}{l}\text { Weight } \\
\text { in grams }\end{array}$ & Alkalinity of Blood-Serum & Quantity of Phosphoric Acid \\
\hline July & 9 & $4^{200}$ & $\frac{\mathrm{N}}{2 \mathrm{O}}$ (before treatment) & $\begin{array}{l}\text { IoO c.c. } \mathbf{I} \% \text {, given per } \\
\text { rectum. }\end{array}$ \\
\hline " & 10 & 3970 & - & $\begin{array}{l}200 \text { c.c. } 1 \% \text {, given per } \\
\text { rectum in two doses, } \\
\text { one in morning and } \\
\text { one in evening. }\end{array}$ \\
\hline " & I I & 3900 & - & $\begin{array}{l}\text { I00 c.c. } 0.5 \% \text { by mouth } \\
\text { and I00 c.c. I } \% \text { per } \\
\text { rectum. (Animal } \\
\text { seemed ill and very } \\
\text { feeble). }\end{array}$ \\
\hline " & I 2 & 3840 & $\begin{array}{l}N \\
50\end{array}$ & \\
\hline
\end{tabular}

Rabbit killed. Post-mortem, the stomach and duodenum were normal in appearance. Secretin was prepared from the duodenum in the usual way and its activity tested on a cat, anaesthetised with ether; secretin made from a normal rabbit was used as a control.

InJECTION

5 c.c.extract from normal rabbit

5 c.c. ",, injected,

5 c.c. ", normal ",

5 c.c. ", , injected ,
FLow OF JUice

$$
\begin{array}{ll}
\ldots & 0.7 \text { c.c. } \\
\ldots & 0.6 \text { c.c. } \\
\ldots & 0.5 \text { c.c. } \\
\ldots & 0.4 \text { c.c. }
\end{array}
$$

This experiment shows that prosecretin is not abolished by an acid intoxication which differed not in degree but only in duration, from that observed in cases of severe diabetes. In human diabetes 
the duration of the acid-intoxication may extend over months; and it is possible that such a prolonged acidosis may destroy or inhibit the formation of prosecretin. On the other hand, it is equally possible that a deficiency of prosecretin may be causally related to diabetes. If this were so, it would follow that diabetes should result from an experimental reduction of the prosecretin in the intestines; and we are attempting to investigate this point. Until more evidence is forthcoming it is impossible to reach a conclusion as to the nature of the relationship existing between prosecretin and some cases of diabetes.

We wish to express our indebtedness to the Physicians of Guy's Hospital, to Dr. Acland, Dr. Ogle, and to Dr. Andrewes of St. Bartholomew's Hospital, for their kindness in supplying us with clinical cases and post-mortem material.

Part of the expense of this investigation was defrayed by a grant from the Royal Society.

\section{REFERENCES}

Bayliss \& Starling, Proc. Roy. Suc. (1902), Vol. LXIX, p. 352 ; J. of Physiul. (1902), Vol. XXVIII, p. 325 ; ibid. (1903), Vol. XXIX, 174 .

Moore, Edie \& Aloram, this Journal (1906), Vol. I, p. 28.

Edie \& Whitley, this Journal (Ig06), Vol. I, p. 1 I. 